\title{
Male predominance of Type 1 (insulin-dependent) diabetes mellitus in young adults: results from a 5-year prospective nationwide study of the 15-34-year age group in Sweden
}

\author{
G.Blohmé ${ }^{1}$, L. Nyström ${ }^{2}$, H.J.Arnqvist ${ }^{3}$, F.Lithner ${ }^{4}$, B.Littorin ${ }^{5}$, P. O. Olsson ${ }^{3}$, B.Scherstén ${ }^{4}$, L. Wibell ${ }^{6}$ and J. Östman $^{7}$ \\ ${ }^{1}$ Department of Medicine II, Sahlgren's Hospital, University of Gothenburg \\ ${ }^{2}$ Department of Epidemiology and Health Care Research, University of Umeå \\ ${ }^{3}$ Department of Internal Medicine, Regional Hospital, Linköping University \\ ${ }^{4}$ Department of Internal Medicine, Regional Hospital, University of Umeå \\ ${ }^{5}$ Department of Community Health Sciences, University of Lund, Dalby \\ ${ }^{6}$ Department of Internal Medicine, University Hospital, Uppsala, and \\ ${ }^{7}$ Department of Internal Medicine, Huddinge Hospital, Karolinska Institute, Stockholm, Sweden
}

\begin{abstract}
Summary. The incidence of diabetes mellitus in Sweden in the 15-34 year age group was prospectively studied on a nationwide basis, beginning 1 January 1983. A total of 1,214 male and 720 female cases of newly-diagnosed (excluding gestational) diabetes were reported over a 5 -year period. This corresponds to an incidence of 20.5 per $100,000 /$ year in male subjects and 12.7 per $100,000 /$ year in female subjects. Most cases were classified as Type 1 (insulin-dependent) diabetes, with an incidence of 15.9 in males and 8.6 in females. The incidence of Type 1 diabetes decreased gradually with age, while the incidence of Type 2 (non-insulin-dependent) diabetes increased. A male predominance was found in all age groups, with a male-to-female ratio of 1.8:1 for Type 1 diabetes and 1.3:1 for Type 2 diabetes. Maximum blood glucose concentration at diagnosis was significantly higher in
\end{abstract}

males than in females in both Type 1 and Type 2 diabetic subjects. In contrast, the percent desirable weight was significantly higher in females, both in Type 1 and Type 2 diabetic subjects. The difference in diabetes incidence therefore cannot be attributed to any methodological error. The present finding of a marked male predominance after puberty in Type 1 diabetes in an ethnically quite homogeneous population supports the hypothesis that environmental risk factors and life-style are important for the development of the disease.

Key words: Type 1 (insulin-dependent) diabetes mellitus, Type 2 (non-insulin-dependent) diabetes mellitus, incidence, blood glucose, body mass index, percent desirable weight.
Although our understanding of the pathogenesis of Type 1 (insulin-dependent) diabetes is increasing, vital information is still lacking which would help us to identify individuals at risk and to prevent or postpone the onset of the disease. Since only $30-50 \%$ of identical twins are concordant for Type 1 diabetes [1], environmental factors seem to be of substantial pathogenic importance. The prospective recording of cases is necessary to provide the basis for case-control studies concerning pathogenic factors. The incidence of Type 1 diabetes in children and young adults is high in the Scandinavian countries [2-7]. The population in Sweden is stable and ethnically quite homogeneous and the health care system is well-organized and offers unique opportunities for epidemiological studies $[8,9]$.

Since 1 January 1983, all newly-diagnosed young adult diabetic subjects in the 15-34-year age group have been recorded in the Swedish Young Adults Diabetes Register [7]. We decided to make a cut-off point at 35 years of age as we are mainly interested in Type 1 diabetes in young adults. This decision was also based on the supposition that almost all diabetic patients under the age of 35 years are being treated in departments of internal medicine in Sweden which use the same guidelines for classification and treatment.

This paper summarizes and discusses the results of the first 5 years of this ongoing prospective study. It is particularly concerned with age, sex, type of diabetes, body mass index, percent desirable weight and blood glucose level at the time of diagnosis.

\section{Subjects and methods}

A standardized registration form was designed for this investigation. The study has been conducted on a nationwide basis in collaboration with all departments of internal medicine $(n=96)$, endocrinology $(n=2)$, paediatrics $(n=44)$, obstetrics and gynaecology $(n=75)$ and approximately 710 primary health care units.

There are six public health regions in Sweden, each with one university hospital which is responsible for the medical service. For the present study six diabetologists served as contact persons for their respective regional medical institutions. All departments and health care units had a physician who was responsible for the recording procedure. The study was brought to the attention of the physi- 
Table 1. Incidence of diabetes mellitus per 100,000/years in Sweden, 1983-1987, by age, sex and type and 95\% confidence limits (CL)



Population at risk: 1,189,101 males (M) and 1,137,739 females (F)

${ }^{a} p<0.0001$ (15-34-year age group)

cians concerned by letters of introduction, articles in the Journal of the Swedish Medical Association and announcements at various national and regional meetings. Contact with referring physicians were also made through reports of study results every 3-6 months. A list of newly-recorded cases was presented once a year to the responsible physicians for comparison with the local records. The data were entered on the standardized form by the reporting physician: the patient's civic number, name and address, the name and address of the reporting department and physician, circumstances of detection (via screening or clinical symptoms), pregnancy, maximum blood glucose level at diagnosis, height and body weight at diagnosis and the physician's classification of the type of diabetes (Type 1, Type 2, secondary, gestational or type unknown or not yet classified). The term "screening" in this context refers to a situation where the reporting physician has found hyperglycaemia during an ordinary health check-up or during an examination of a patient with ill-defined symptoms. Most cases were reported by senior physicians in departments of internal medicine using the same diabetes classification. Fewer than 100 cases, mainly classified as Type 2 diabetes, were reported by physicians at primary health care units. According to the current practice in Sweden, cases characterized by low or normal body weight, low age, severe hyperglycaemia, ketosis and an immediate need for insulin therapy are regarded as Type 1. Obesity, few symptoms and considerable improvement following dietary measures, alone or in combination with sulphonylurea, indicate the presence of Type 2 . In this presentation, patients with gestational diabetes are not included; gestational diabetes is defined as diabetes mellitus or impaired glucose tolerance with onset or first recognition during the current pregnancy and normalization without antidiabetic treatment after delivery. Body mass index was calculated from the reported values for height and weight $\left(\mathrm{kg} / \mathrm{m}^{2}\right)$. The body weight was not corrected for weight loss during the pre-diagnostic period. Percent desirable weight (PDW), which is derived from the medium frame ideal body weight estimates of the Society of Actuaries [10], was calculated as body mass index $\times 4.76$ for females and body mass index $\times 4.39$ for males.

As regards diagnostic criteria, the physician completing the registration form was asked to consider the following alternatives: (1) fasting blood glucose $\geq 7.0 \mathrm{mmol} / \mathrm{l}$ and/or random blood glucose $\geq 10.0 \mathrm{mmol} / \mathrm{l}$; (2) fasting blood glucose $<7.0 \mathrm{mmol} / \mathrm{l}$ and impaired glucose tolerance; (3) fasting blood glucose $<7.0 \mathrm{mmol} / \mathrm{l}$ and oral glucose tolerance test (OGTT) not performed. The third alternative was designed for patients considered to have diabetes on the grounds of an earlier history of the disease - for example, gestational diabetes - where the physicians concluded that a slightly elevated blood glucose concentration did not call for an OGTT to verify the diagnosis. A total of $93 \%, 6 \%$ and $1 \%$ of the reported cases were registered according to alternatives 1,2 and 3 , respectively. Thus, only a few cases $(n=20)$ in this large cohort had a diagnosis which was not clearly verified. All patients classified according to alternatives 2 and 3 were considered as Type 2 diabetic subjects.

A study of the validity of the registration was conducted by use of the Patient Administration System (PAS-IC) [11], which is a computer-based system for registering the hospital admittance and care of in-patients. This validity study was performed in the counties of Malmöhus and Kristianstad in the south of Sweden, which have $9.2 \%$ of the Swedish 15-34-year-old population. Since there was a possibility that patients might have been missed by both systems and registers, we used the methodology based on the principle of the two-sample capture-recapture phenomenon [12]. In this validity test, a quite high detection level was found for Type 1 diabetes = 0.86 . For Type 1 and Type 2 diabetes taken together, the detection level was 0.79 with no difference between the genders. Since the ascertainment of newly-diagnosed diabetic cases is not known for the other counties in Sweden no correction of the primary incidence data has been performed.

The study was approved by the Ethics Committee of the Karolinska Institute in Stockholm. Permission to use the Swedish national civic registration number in our data base was granted by the Swedish Inspection Board.

\section{Statistical analysis}

Data were collected and analysed in the Department of Epidemiology and Health Care Research, Umeå. Population data from the publications of "Statistics, Sweden", were used to calculate age- and sex-specific incidences. Incidence rates (per 100000 and year) and $95 \%$ confidence intervals were calculated. The Student's $t$-test was used to determine whether the difference between the sexes was due to chance.

\section{Results}

A total of 1,214 male and 720 female cases of newly-diagnosed, but not gestational, diabetes were reported in the 15-34-year age group in Sweden during the period 1983-1987 (Table 1). The populations at risk were 1,189, 101 males and 1,137,739 females. The incidence was significantly higher $(\mathrm{p}<0.001)$ in males $(20.5 / 100,000 /$ year $)$ than in females (12.7/100,000/year). Among males, $77.4 \%$ were classified as Type 1 and $15.2 \%$ as Type 2 diabetic 
Table 2. Mean maximum blood glucose level and mean percent desirable weight (PDW) - comparison by sex and type of diabetes

\begin{tabular}{|c|c|c|c|c|c|c|}
\hline \multirow[t]{2}{*}{ Type of diabetes } & \multicolumn{2}{|c|}{ Maximum blood glucose level $(\mathrm{mmol} / \mathrm{l})$} & \multirow[t]{2}{*}{$p$} & \multicolumn{2}{|l|}{ PDW } & \multirow[t]{2}{*}{$p$} \\
\hline & Males & Females & & Males & Females & \\
\hline $\begin{array}{l}\text { Type } 1 \text { (insulin- } \\
\text { dependent) }\end{array}$ & $23.0(985)$ & $21.6(516)$ & $<0.001$ & $94.5(958)$ & $99.6(499)$ & $<0.0001$ \\
\hline $\begin{array}{l}\text { Type } 2 \text { (non-insulin- } \\
\text { dependent) }\end{array}$ & $15.2(206)$ & $13.6(151)$ & $<0.003$ & $123.4(196)$ & $134.5(146)$ & $<0.003$ \\
\hline$p$ & $<0.0001$ & $<0.0001$ & & $<0.0001$ & $<0.0001$ & \\
\hline
\end{tabular}

Number of patients investigated in parentheses

subjects, and $4.9 \%$ were not classifiable. The corresponding figures for females were $67.4 \%, 18.9 \%$ and $11.3 \%$, respectively. The incidence of Type 2 diabetes was slightly higher in males, but not significantly so. Only a few patients had secondary diabetes $(n=49)$ with the majority being in the 30-34 year age group. Pancreatitis was the most common underlying disease, but a number of other disorders were present, such as Cushing's syndrome, acromegaly, glucagonoma, pancreatic carcinoma and the Prader-Willi syndrome.

The incidence of Type 1 diabetes seemed to decrease gradually with age in both sexes, while the incidence of Type 2 diabetes increased slowly. Thus, in the youngest age group (15-19 years) $91 \%$ of males and $84 \%$ of females were classified as Type 1 diabetic subjects, while in the oldest age group (30-34 years) the corresponding figures were $59 \%$ and $45 \%$, respectively. A male predominance of Type 1 diabetes was found in all age groups, with a male-to-female ratio varying from $1.6: 1$ to $2.3: 1$ with a mean of $1.8: 1$.

At diagnosis a maximum blood glucose concentration $\geq 15 \mathrm{mmol} / \mathrm{l}$ was recorded in approximately $91.9 \%$ of males registered as Type 1 diabetic subjects but in less than $49.2 \%$ of patients registered as Type 2 diabetic subjects (Fig. 1a). The findings in females were essentially the same, $88.6 \%$ and $33.3 \%$, respectively (Fig. $1 \mathrm{~b}$ ). The mean maximum blood glucose level was significantly higher $(23.0 \mathrm{mmol} / \mathrm{l})$ in males with Type 1 diabetes than in males with Type 2 diabetes $(15.2 \mathrm{mmol} / \mathrm{l})(p<0.0001)$ (Table 2). The corresponding figures in females were $21.6 \mathrm{mmol} / \mathrm{l}$ (Type 1 ) and $13.6 \mathrm{mmol} / 1$ (Type 2 ), respectively $(p<0.001)$. Thus, the maximum blood glucose levels at diagnosis were higher in males than in females, irrespective of the type of diabetes.

A body mass index exceeding $25 \mathrm{~kg} / \mathrm{m}^{2}$ at diagnosis was reported in $11.8 \%$ of males and $12.0 \%$ of females, classified as having Type 1 diabetes (Fig. 2a,b), and in as many as $63.8 \%$ of males and $64.6 \%$ of females with Type 2 diabetes. PDW was significantly higher in females, with both Type $1(p<0.0001)$ and Type 2 diabetes $(p<0.003)$ (Table 2).

Among patients classified as having Type 1 diabetes $90.6 \%$ were diagnosed as a result of clinical symptoms, whereas the corresponding figure for patients classified as Type 2 diabetic subjects was $54.9 \%$. Thus, almost half of the patients classified as Type 2 diabetic subjects were diagnosed in connection with a general examination because of ill-defined symptoms or as part of a health checkup.

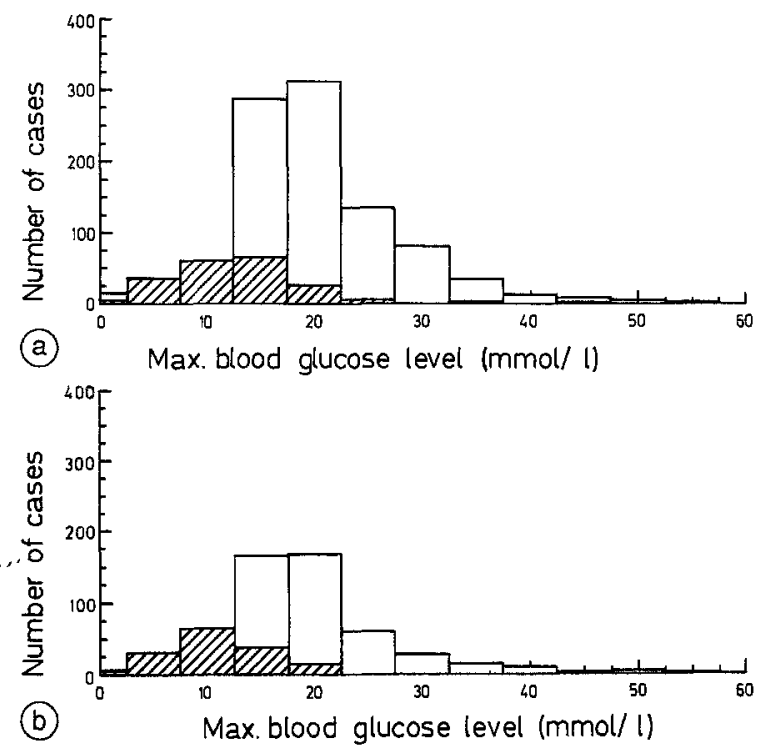

Fig. 1a-b. Distribution of maximum blood glucose concentrations within two weeks of diagnosis: $\mathbf{a}$ in males with Type 1 (insulin-dependent) and Type 2 (non-insulin-dependent) diabetes mellitus; b in females with Type 1 and Type 2 diabetes. Type 1 diabetes $(\square)$; Type 2 diabetes (ZZ)
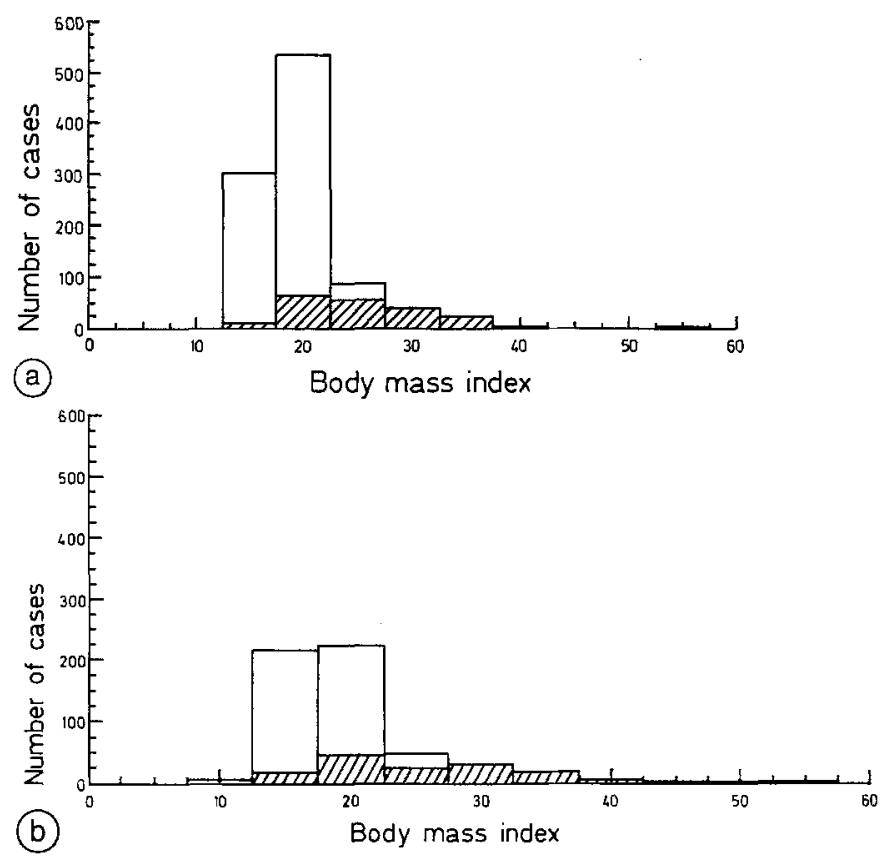

Fig. 2a-b. Distribution of body mass index $\left(\mathrm{kg} / \mathrm{m}^{2}\right)$ at the time of diagnosis: a in males with Type 1 (insulin-dependent) and Type 2 (non-insulin-dependent) diabetes; $b$ in females with Type 1 and Type 2 diabetes. Type 1 diabetes $(\square)$; Type 2 diabetes $(\square)$ 
Table 3. Age- and sex-specific annual incidence rates of diabetes registered world wide (1925-1987)

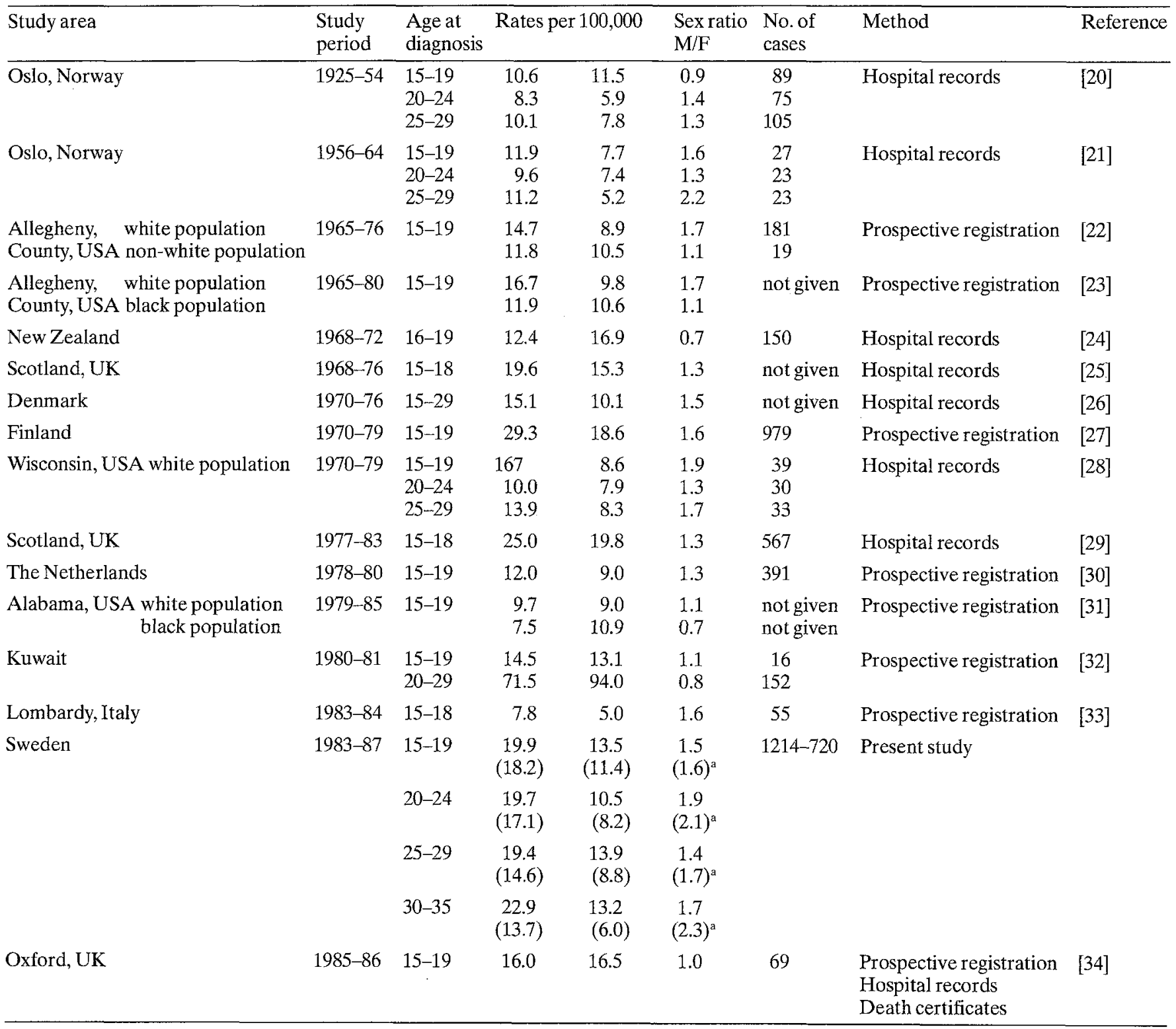

\footnotetext{
a Type 1 in parentheses
}

\section{Discussion}

This prospective ongoing incidence study of diabetes in the 15-34-year age group in Sweden was conducted on a nationwide basis and involved physicians in more than 100 hospital departments and in more than 700 primary health care units. For efficient co-operation, the recording of cases was made as simple as possible with regard to diagnostic procedure/criteria that are generally accepted in Sweden.

Our diagnostic criteria may be compared with those established by the World Health Organisation (WHO) in 1979 [13], WHO in 1985 [14], Teuscher and Jarrett [15] and the National Diabetes Data Group (NDDG) [10] which require a fasting venous or capillary whole blood glucose concentration of $\geq 7.0, \geq 6.7,>7.0$ and $\geq 6.7 \mathrm{mmol} / 1$, respectively, and $/$ or $\geq 10.0 \mathrm{mmol} / \mathrm{l}$ for venous blood or $\geq 11.1 \mathrm{mmol} / 1$ for capillary whole blood after a $75 \mathrm{~g}$ oral glucose load. An insignificant number of individuals reported as Type 2 diabetic subjects with borderline values may not have fulfilled strict diagnostic criteria, using a standardized glucose tolerance test and a strict analytical procedure throughout the country. The finding that only a very small number of subjects had a maximum blood glucose of $<10.0 \mathrm{mmol} / \mathrm{l}$ supports the view that the risk of over-reporting was low.

Concerning the risk of under-reporting, a quite high detection level (0.86) was found for Type 1 diabetes. Since our study is ongoing and diabetes is a chronic disease for which the responsible physicians are repeatedly asked to check their records, some patients who may have been initially overlooked can be expected to be reported later on, so that the risk of under-reporting will gradually decrease. Type 2 diabetes was detected during an asymptomatic period in about $50 \%$ of the patients. This type of casefinding is more developed in some primary health care 
units than in others, which indicates that significant underreporting is likely. Our conclusion is that the incidence data reported in this study are minimal rates and that the true figures may be $10 \%$ higher for Type 1 diabetes and $20 \%$ higher for Type 2 diabetes, particularly in patients over the age of 30 years.

At diagnosis in some cases it may be difficult or impossible to classify the type of diabetes. Thus, in some non-obese patients with initial mild hyperglycaemia progressing to insulin-dependency after some months or years, it is uncertain whether they should be classified as Type 1 with slow onset or as Type 2 subjects [17,18]. When the NDDG criteria [10] were applied to some hundreds of diabetic patients, more than one third could not be classified as either Type 1 or Type 2 diabetic subjects [19]. In the present study, in which the classification was based on the clinical experience of the reporting physician, a certain degree of misclassification may be expected. The distribution curves also show an overlapping of maximum blood glucose levels and body mass indexes, although the mean values differ significantly between subjects classified as Type 1 and Type 2 diabetic patients. This report covers the first 5 years of a prospective ongoing study in Sweden. We have now included the measurement of islet-cell antibodies, HLA-DQ polymorphism and C-peptide at diagnosis to further characterize these young diabetic subjects. This will be reported at a later stage. Until we have more accurate and independent methods of identifying patients in certain groups our classification of young adult diabetic patients at Type 1 or Type 2 will be only approximate.

The total incidence of diabetes in Sweden in the 1534-year age group was high throughout the study period, with a moderate year-to-year variation. The mean annual incidence (per 100,000) was 20.5 for males and 12.7 for females. When our incidence rates were restricted to reported Type 1 diabetic subjects we found the incidence to be 15.9 for males and 8.6 for females and in the 15-19-year age group, 18.2 and 11.4, respectively. The previously reported incidence data in the literature are summarized in Table 3 [20-34]. This shows that the recent incidence rate in Sweden is lower than those reported in Finland [28] and recently in Scotland, UK [29], but higher than previously reported in Oslo [20, 21], Allegheny, USA [22, 23], New Zealand [24], Scotland, UK [25], Denmark [26], Wisconsin, USA [28], The Netherlands [30], Alabama, USA [31], Kuwait [32], Lombardy, Italy [33] and Oxford, UK [34]. Only a limited number of studies, usually retrospective, have been undertaken in the 20-35 year age group namely in Oslo [20, 21], Denmark [26] and Wisconsin, USA [28]. The current incidence of diabetes in Sweden was significantly higher than in those studies. However, it was considerably lower than in the 20-29-year age group in $\mathrm{Ku}$ wait, which has the highest incidence rate so far reported in the world 71.5 in males and 94.0 in females. More than two thirds of these patients were on diet treatment alone or on oral hypoglycaemic drugs. It is not known whether the third of the patients who were treated with insulin had Type 1 or Type 2 diabetes.

The male predominance reported in the first year of this study [7] was also noted in the 5-year study, with an overall male-to-female ratio of $1.6: 1$ and $1.8: 1$ for those reported with Type 1 diabetes. The initial maximum blood glucose level was significantly higher in males than in females, regardless of the type of diabetes. Moreover, PDW at diagnosis was lower in males with Type 1 or Type 2 diabetes. The percentages of males and females classified as having Type 2 diabetes, on the grounds of clinical symptoms, were almost the same. Thus, it seems likely that males with Type 2 diabetes were not misclassified as Type 1 diabetic subjects to a greater extent than females. There is no clear explanation as to why males with Type 1 diabetes had a higher blood glucose level and a lower PDW at diagnosis. One interpretation may be that males wait longer before they go to see a doctor or that the destruction of the Beta cells is more rapid. The possibility that either Type 1 or Type 2 diabetes had been incorrectly diagnosed as gestational diabetes might explain the high male-to-female ratio has been discussed previously [7]. Thus, analyses of the first-year data showed that females recorded as having gestational diabetes had normal or only slightly elevated blood glucose levels which normalized after delivery without anti-diabetic treatment. An incorrect diagnosis of gestational diabetes therefore only accounted for a very small, if any, difference in incidence between males and females. Furthermore, in the present study the sex ratio was the same in the 15-19-year age group, in which practically no patients with gestational diabetes were reported, as in the three older age groups.

Concerning the male predominance this has been previously observed, even if it was less marked than in the present study, in the 15-19-year age group in a number of studies, for example Oslo [21], Allegheny, USA [22, 23], Scotland, UK [25], Finland [27], Wisconsin, USA [28], The Netherlands [30] and Lombardy, Italy [33]. The reason why this has not been previously emphasized may be that the number of cases in these studies, except in Finland [27], Scotland, UK [29] and The Netherlands [30], was rather small and no attempt was made to examine possible errors underlying the observed sex differences.

The high male-to-female ratio is apparently not obvious until the post-pubertal years; it starts between 13 and 14 years, before which age there is a similar incidence in both sexes [2-5]. The increase in the male-tofemale ratio after puberty indicates that sex hormones may have an impact on the incidence of diabetes. An increased susceptibility to viral and bacterial infections may be one explanation. It has been shown that sex differences - with male predominance - occur in the incidence of mumps [35], Coxsackie B virus [35-37], adenovirus [38], echovirus [35, 39] and polio virus [35] infections in children. It has been hypothesized that differences in susceptibility to infections may be related to a Y-linked histocompatibility locus [39]. However, no male predominance was found in adults $[36,37]$. No difference in the frequency of IgM antibodies against Coxsackie B virus serotypes has been found in two recent studies performed in children with newly-diagnosed Type 1 diabetes $[40,41]$. The importance of virus infections for the development of Type 1 diabetes is still uncertain [42], and the present finding of male predominance does not allow any conclusions to be drawn concerning increased suscepti- 
bility to virus infections in males. Differences in the lifestyle of males may also have an impact on the incidence of diabetes and the findings call for further studies in this respect. This may explain why Type 1 diabetes is more common in males, despite the fact that this disease is associated with other autoimmune diseases showing a significant female predominance, such as thyroid diseases $[43,44]$. In this connection it is of interest that a higher male incidence of Type 1 diabetes has been noted in Germany [45] starting at the age of 25-30 years and including the 50-55-year-age group (Michaelis D: personal communication). Further studies on the aetiology of Type 1 diabetes should take into consideration the finding that the male predominance that is seen after puberty, appears to gradually increase.

Acknowledgements. This study was supported by grants from the Swedish Medical Research Council, project (B88-27X-07970-02B), the Swedish Council for Planning and Co-ordination of Research (870066:2, 880103:2), the Swedish Diabetes Association, Nordic Insulin Foundation and the Swedish Diabetes Foundation. We also wish to thank all the physicians and nurses who helped to complete the registration forms for the patients who participated in this study.

\section{References}

1. Barnett AH, Eff C, Leslie RDG, Pyke DA (1981) Diabetes in identical twins. Diabetologia 20: 87-93

2. Dahlquist G, Gustavsson KH, Holmgren G et al. (1982) The incidence of diabetes mellitus in Swedish children 0-14 years of age. A prospective study 1977-1980. Acta Paediatr Scand 71: 7-14

3. Dahlquist G, Blom L, Holmgren G et al. (1985) The epidemiology of diabetes in Swedish children 0-14 years - a six-year prospective study. Diabetologia 28: 802-808

4. Akerblom HK, Reunanen A (1985) The epidemiology of insulindependent diabetes mellitus (IDDM) in Finland and in northern Europe. Diab Care 8 [Suppl 1]: 10-16

5. Diabetes Epidemiology Research International Group (1988) Geographic patterns of childhood insulin-dependent diabetes mellitus. Diabetes 37:1113-1119

6. Christau B, Kromann H, Ortved Andersen O et al. (1979) Incidence of insulin-dependent diabetes mellitus $(0-29$ years at onset) in Denmark. Acta Med Scand [Suppl 624]: 54-60

7. Östman J, Arnquist H, Blohmé G et al. (1986) Epidemiology of diabetes mellitus in Sweden. Acta Med Scand 220: 437-445

8. Tibbling G (1967) High blood pressure in men aged 50-A population study of men born in 1913. Acta Med Scand [Suppl 479]

9. Bengtsson C, Blohmé G, Hallberg L et al. (1973) The study of women in Gothenburg 1968-1969 - a population study. General design, purpose and sampling results. Acta Med Scand 193:311318

10. National Diabetes Data Group (1979) Classification and diagnosis of diabetes mellitus in all categories of glucose intolerance. Diabetes 28: 1039-1057

11. Lithman T (1982) Data systems in health planning. An evaluation of population-based data systems as tools for health planning. Thesis, Lund University

12. Bishop YMM, Fienberg SE, Holland PW (1974) Discrete multivariate analysis: theory and practice. MIT Press, Massachusetts, pp 229-237

13. World Health Organization Expert Committee (1980) Second report on diabetes mellitus. Technical Report, series no.646, Geneva, Switzerland

14. World Health Organization Expert Committee (1985) Diabetes mellitus. Technical Report, series no. 742, Geneva, Switzerland
15. Teuscher A, Jarrett RJ (1984) Diabetes mellitus: diagnostic criteria. Diab Med 1: 305-307

16. Wilson RM, van der Minne P, Deverill I et al. (1985) Insulin dependence: problems with the classification of 100 consecutive patients. Diab Med 2: 167-172

17. Tarn AC, Smith CP, Spencer KM, Botazzo GF, Gale EAM (1987) Type 1 (insulin-dependent) diabetes: a disease of slow clinical onset? Br Med J 294: 342-345

18. Groop LC, Bottazzo GF, Doniach D (1986) Islet cell antibodies identify latent type 1 diabetes in patients aged $35-75$ years at diagnosis. Diabetes 35: 237-241

19. Abourizk NN, Dunn JC (1990) Types of diabetes according to national diabetes data group classification. Diab Care 13: 1120 1123

20. Westlund K (1966) Incidence of diabetes mellitus in Oslo, Norway, 1925 to 1954. Br J Prev Soc Med 20: 105-116

21. Ustvedt HJ, Olsen E (1977) Incidence of diabetes mellitus in Oslo, Norway, 1956-65. Br J Prev Soc Med 31: 251-257

22. LaPorte RE, Fishbein HA, Drash AL et al. (1981) The Pittsburgh insulin-dependent diabetes mellitus (IDDM) registry. The incidence of insulin-dependent diabetes mellitus in Allegheny county, Pennsylvania (1965-1976). Diabetes 30: 279-284

23. LaPorte RE, Tajima N, Dorman JS et al. (1986) Difference between blacks and whites in the epidemiology of insulin-dependent diabetes mellitus in Allegheny County, Pennsylvania. Am J Epidemiology 123: 592-603

24. Crossley JR, Upsdell M (1980) The incidence of juvenile diabetes mellitus in New Zealand. Diabetologia 18: 29-34

25. Patterson CC, Thorogood M, Smith PG, Heasman MA, Clarke JA, Mann II (1983) Epidemiology of Type 1 (insulin-dependent), diabetes in Scotland 1968-1976: evidence of an increasing incidence. Diabetologia 24: 238-243

26. Cristau B, Kromann H, Christy M, Ortved Andersen O, Nerup J (1979) Incidence of insulin-dependent diabetes mellitus (0-29 years at onset) in Denmark. Acta Med Scand [Suppl 624]: 54-60

27. Reunanen A, Akerblom HK, Käär ML (1982) Prevalence and ten year (1970-79) incidence of insulin-dependent diabetes mellitus in children and adolescents in Finland. Acta Paediatr Scand 71: 893-899

28. Allen C, Palta M, D'Alessio DJ (1986) Incidence and differences in urban-rural seasonal variation of Type 1 (insulin-dependent) diabetes in Wisconsin. Diabetologia 29:629-633

29. Patterson CC, Smith PG, Webb J, et al. (1988) Geographical variation in the incidence of diabetes mellitus in Scottish children during the period 1977-1983. Diab Med 5: 160-165

30. Vaandrager GJ, Bruining GJ, Veenhof FJ, et al. (1984) Incidence of childhood diabetes in the Netherlands: a decrease from north to south over north-western Europe? Diabetologia 27: 203-206

31. Wagenknecht LE, Roseman JM, Alexander WJ (1989) Epidemiology of IDDM in black and white children in Jefferson County, Alabama, 1979-1985. Diabetes 38: 629-633

32. Taha TH, Moussa MMA, Rashid AR, Fenech FF (1983) Diabetes mellitus in Kuwait. Incidence in the first 29 years of life. Diabetologia 25: 306-308

33. Calori G, Gallus G, Garancini P, Repetto F, Micossi P (1990) Identification of the cohort of type 1 diabetes presenting in Lombardy in 1983-84: a validated assessment. Diab Med 7: 595-599

34. Bingley PJ, Gale EAM (1989) Incidence of insulin-dependent diabetes in England: a study in the Oxford region, 1985-86. Br Med J 298: 558-560

35. Lennette EH, Magoffin RL, Knouf EG (1962) Viral central nervous system disease. An etiologic study conducted at the Los Angeles County General Hospital. JAMA 179: 687-695

36. Public Health Laboratory Service, United Kingdom and Republic of Ireland (1971) Epidemiology. Coxsackie B virus. Br Med J 2: 178

37. Public Health Laboratory Service, United Kingdom and Republic of Ireland (1972) Epidemiology. Coxsackie B virus infections in 1971. Br Med J 1: 453

38. Sutton RNP, Pullen HJM, Blackledge P, Brown EH, Sinclair L, Swift PN (1976) Adenovirus type 7; 1971-74. Lancet II: $987-991$ 
39. Editorial (1976) H-Y antigens. Lancet II: 1008

40. Friman G, Fohlman J, Frisk G, et al. (1985) An incidence peak of juvenile diabetes. Relation to Coxsackie $B$ virus immune response. Acta Paediatr Scand [Suppl 320]: 14-19

41. Tuvemo T, Dahlquist G, Frisk G, et al. (1989) The Swedish childhood diabetes study III: IgM against Coxsackie B viruses in newly diagnosed Type 1 (insulin-dependent) diabetic children no evidence of increased antibody frequency. Diabetologia 32: 745-747

42. Yoon JW, Kim CJ, Pak CY, McArthur RG (1987) Effects of environmental factors on the development of insulin-dependent diabetes mellitus. Clin Invest Med 10: 457-469

43. Tunbridge WMG, Evered DC, Hall R, et al. (1977) The spectrum of thyroid disease in a community: The Wickham survey. Clin Endocrinol 7: 481-493

44. Eggertsen R, Petersen K, Lundberg PA, et al. (1988) Screening for thyroid disease in a primary care unit with a thyroid stimulat- ing hormone assay with a low detection limit. Br Med J 297: $1586-1592$

45. Michaelis D, Jutzi E (1987) Epidemiological trends of diabetes duration in the diabetic population of the G.D.R. Diabetologia 30:557A (Abstract)

Received: 5 April 1991

and in revised form: 9 September 1991

Dr. J.Östman

Department of Internal Medicine

Huddinge Hospital

Karolinska Institute

S-141 86 Huddinge

Sweden 